\title{
Evaluation of the Effect of Silver Nanoparticles on Induction of Neutralizing Antibodies against Inactivated Rabies Virus
}

\author{
Vahid Asgary ${ }^{1,2}$, Omid Kord Mafi ${ }^{3}$, Mohammad Sadeq Khosravy ${ }^{4}$, Alireza Janani ${ }^{1}$, \\ Nabiollah Namvar Asl ${ }^{4}$, Rouzbeh Bashar ${ }^{1}$, Hadi Poortaghi ${ }^{5}$, Hossein Ahangari Cohan ${ }^{5}$, Alireza Shoari ${ }^{6}$, \\ Reza Ahangari Cohan ${ }^{1} *$ \\ 1 Department of Rabies, Virology Research Group, Pasteur Institute of Iran, Tehran, Iran \\ 2 Department of Immunology, School of Medicine, Tehran University of Medical Sciences, Tehran, Iran \\ 3 Department of Biotechnology, Payam-e-Nour University, East Branch, Tehran, Iran \\ 4 Department of Laboratory of Animal Sciences, Pasteur Institute of Iran, Tehran, Iran \\ 5 Faculty of Veterinary Medicine, Islamic Azad University, Karaj, Iran \\ 6 Department of Molecular and Cellular Biology, Islamic Azad University, Pharmaceutical Sciences Branch, Tehran, Iran
}

Received Jan 25, 2014; Accepted May 28, 2014

\begin{abstract}
:
Introduction: Nanoparticles have been considered as promising tools because of their high applicability. Recently, nanoparticles have been evaluated for their ability to increase the immune responses as adjuvants. Silver-nanoparticles (AgNPs) have shown promising results in enhancing Th-2 immune responses and to produce potent neutralizing antibodies. Neutralizing antibodies are considered as the main defense mechanism in preand post-exposure treatments of rabies disease. Therefore in this study, the effects of AgNPs in enhancing the immunogenicity of inactivated rabies virus were assessed. Methods: Different concentrations of AgNPs $(0.2$, $0.4,0.6$ and $0.8 \mathrm{mg} / \mathrm{ml}$ ) were added to inactivated rabies virus. Mice were immunized by two intra-peritoneal injections of each concentration on days 1 and 7. The inactivated virus and Alum were used as negative and positive controls, respectively. Blood was collected from healthy and immunized mice, one week after the last immunization. Serum was isolated from each sample and the amounts of neutralizing antibodies were determined by Rapid Florence Focus Inhibition Test (RFFIT). The cytotoxicity of AgNPs was also assessed by in vitro MTT assay on J774A. 1 cell line. Results: The results showed that $0.4,0.6$ and $0.8 \mathrm{mg} / \mathrm{ml}$ of AgNPs had significantly increased the immune responses compared to the control; however, $0.2 \mathrm{mg} / \mathrm{ml}$ of AgNPs did not show a significant effect. No cytotoxicity was observed for 0.001 and $0.01 \mathrm{mg} / \mathrm{ml}$ concentrations of AgNPs but cell viability was decreased significantly at $0.1 \mathrm{mg} / \mathrm{ml}$ concentration. Conclusion: It was shown that the virus-loaded AgNPsat $0.4 \mathrm{mg} / \mathrm{ml}$ concentration could raise the neutralizing antibodies against rabies virus in mice, but their adverse effect on cell viability excludes their use as an adjuvant. Vac Res, 2014, 1 (1): 31-34
\end{abstract}

Keywords: Adjuvant, Silver Nanoparticle, Rabies Vaccine, Neutralizing Antibodies.

\section{INTRODUCTION}

Vaccination is one of the most effective approaches in managing healthcare costs in all countries. Unfortunately, the vaccines do not usually show good immunogenic properties similar to native microorganisms because of either the chemical modifications or not using whole live microorganisms [1]. In many cases, adjuvants are employed to evoke more powerful immune responses. An optimally-formulated adjuvant must be safe, sta- ble before administration, readily biodegradable, able to promote an antigen-specific immune response, inexpensive to produce and easy to use [2]. Until recently however, only one type of adjuvant, aluminum salts (e.g.

*Corresponding Author: Reza Ahangari Cohan

Department of Rabies, Virology Research Group, Pasteur Institute of

Iran, No. 69, Pasteur Ave, Tehran, Iran, 1316943551.

Email: Cohan_r@yahoo.com

Tel/Fax: +98 2166403496 
Alum), has been widely used with licensed human vaccines [3], even though a variety of novel adjuvants have been evaluated in the past few decades, such as oligonucleotides and various emulsions [4]. The adjuvants enhance the immunogenicity through sustained release of an antigen at injection sites and stimulation of the innate immunity $[5,6]$. Due to the limited adjuvant effect of the aluminum salts, constant mutation of existing microbes and identification of new disease-causing microorganisms, the search for more effective adjuvants is continuing $[7,8]$.

Nanoparticles have been considered as promising tools because of their high applicability. Recently, nanoparticles are evaluated for their ability to increase the immune responses as adjuvants. The dimensions of artificial nanoparticles can be controlled from nanometer to micrometer scales which improve the flexibility and quality of the newly-developed vaccines.

The size of the nanoparticles can be easily changed to imitate the virus particles, hence confirming their usefulness in vaccine designs.

Employment of nanoparticles with entrapped or adsorbed biomolecules like nucleic acids or proteins represents a promising approach for controlled delivery of the antigens and optimizing the preferred immune responses by means of selective targeting of the antigen presenting cells (APCs). The targeted delivery of the antigens to APCs, especially Dendritic Cells (DCs) and the stimulation of APCs are the major issues in the development and improvement of potent vaccines. Moreover, the nanoparticle-based vaccine systems create opportunities to control the delivery of the antigens to special immune system cells in order to invoke more potent immune responses [9].

Recently, the silver nanoparticles (AgNPs) have been evaluated for their effect on the immune system. Two protein models were investigated and the primary results have shown increased humeral immune responses leading to the rise of neutralizing antibodies. Surprisingly, this effect by AgNPs was comparable to the effects caused by a commercially available adjuvant (i.e. Alum) when administrated subcutaneously in one protein model. Furthermore, no toxicity was observed in the used range of concentrations of AgNPs as an adjuvant which could be considered as a promising result in the adjuvant area [10]. Rabies is a progressive encephalitis disease which finally leads to death. Pre- and post-exposure treatment schedules are the only effective approach for the control of the disease, resulting in the increase of neutralizing antibodies against rabies virus. Vaccination plays a key role in prevention of the disease outbreaks and more potent vaccines are required for this purpose [11].

Therefore in the current study, the ability of AgNPs to evoke immune responses against rabies virus was investigated and the results were compared to Alum.

\section{MATERIALS AND METHODS}

Loading of inactivated rabies virus on AgNPs. Onehalf $\mathrm{ml}$ of inactivated virus (Pasteur Institute of Iran, Lot Number: 92-2) was added to AgNPs (Sigma-Aldrich,
USA, size $<100 \mathrm{~nm})$ at different concentrations $(0.2,0.4$, 0.6 and $0.8 \mathrm{mg} / \mathrm{ml}$ equal to $5,10,15$ and $20 \mathrm{mg} / \mathrm{kg}$ ) and the mixture was incubated overnight at $4{ }^{\circ} \mathrm{C}$ with gentle stirring. Four groups of six female NMRI mice (average weight $\sim 20 \mathrm{~g}$, Pasteur Institute of Iran) were used for in vivo test. In addition, Rabies vaccine (containing Alum, Pasteur Institute of Iran) and the inactivated virus (without Alum, Pasteur Institute of Iran) were used as positive and negative controls, respectively.

Mice were injected intra-peritoneally (i.p.) twice with $0.5 \mathrm{ml}$ of each vaccine on days 1 and 7 and their blood samples were collected one week later (day 14). The sera were subsequently isolated by centrifugation at $5000 \mathrm{rpm}$ for $10 \mathrm{~min}$ after $1 \mathrm{~h}$. incubation at RT and were stored at $-20^{\circ} \mathrm{C}$ for further analysis.

In vitro toxicity of AgNPs. J774A.1 cell line (ATCC TIB-67) were cultured in DMEM supplemented with 10 $\% \mathrm{FBS}$ and $1 \mathrm{X}$ Pen-Strep (Invitrogen, USA) at $37^{\circ} \mathrm{C}$ and $5 \%$ CO2. For MTT assay, 20,000 cells/well were cultured in a 96-well plate (Nunc, USA) and incubated overnight at $37^{\circ} \mathrm{C}$ and $5 \% \mathrm{CO} 2$. Different concentrations of AgNPs $(10-3,10-2,10-1$ and $1 \mathrm{mg} / \mathrm{ml})$ were added to each well as triplicates and incubated for $24 \mathrm{~h}$ at $37^{\circ} \mathrm{C}$. One-hundred $\mu 1$ $(0.5 \mathrm{mg} / \mathrm{ml})$ of MTT (Sigma-Aldrich, Germany) was then added to each well and incubated for $4 \mathrm{~h}$ at $37^{\circ} \mathrm{C}$.

The supernatants were removed and $100 \mu 1$ DMSO (Sigma, USA) was added to each well and the reaction read at 570 and $630 \mathrm{~nm}$. Data was analyzed by SPSS version 16.0 using independent t-test.

Determination of neutralizing antibody titers by RFFIT. The isolated sera were inactivated by incubation at $56^{\circ} \mathrm{C}$ for $30 \mathrm{~min}$ and three-fold serial dilutions of reference (WHO Reference) and sample sera were prepared in MEM medium in triplicates. Subsequently, $50 \mu 1$ of live rabies virus (CVS-11 strain, Pasteur Institute of Iran, Iran) sufficient to infect $80 \%$ of cells in each well was added to each well and incubated at $37^{\circ} \mathrm{C}$ for $1 \mathrm{~h}$ MEM instead of CVS and PBS instead of serum were used as negative and positive controls, respectively. Fifty $\mu 1$ of BSR cell suspension in MEM supplemented with $10 \%$ FBS $(5 \times 104$ cells/well) was added to each well and incubated overnight at $37^{\circ} \mathrm{C}$ and $5 \% \mathrm{CO} 2$.

The plates were rinsed three times with PBS and fixed using $80 \%$ cold acetone for $30 \mathrm{~min}$ at $4^{\circ} \mathrm{C}$. Finally, the plates were stained with $50 \mu \mathrm{l}$ FITC-conjugated anti-nucleocapsid polyclonal antibody (Bio-Rad, USA) and the percentage of the infection was determined by fluorescent microscopy. The neutralizing antibody titers were calculated using Reed and Muench method [12].

\section{RESULTS}

Determination of neutralizing antibody titers by RFFIT. Statistical analysis showed that $0.4,0.6$ and $0.8 \mathrm{mg} /$ $\mathrm{ml}$ of AgNPs had a significant effect on the immune response, as measured by the level of neutralizing antibodies compared to the inactivated virus (without adjuvant; Fig. 1) while $0.2 \mathrm{mg} / \mathrm{ml}$ of AgNPs did not show a significance effect ( $p$ value $>0.05)$. 
In groups receiving AgNPs, no significant difference was observed between 0.6 and $0.8 \mathrm{mg} / \mathrm{ml}$ of AgNPs whereas injection with $0.4 \mathrm{mg} / \mathrm{ml} \mathrm{AgNPs}$ caused a significant difference. Although the positive control group (Alum) had the highest level of neutralizing antibody (Fig. 1), the statistical analysis did not show any significant differences regarding the 0.6 and $0.8 \mathrm{mg} / \mathrm{ml}$ groups.
In vitro toxicity of AgNPs. The toxicity of AgNPs was determined by MTT assay and the results demonstrated no toxicity with 0.001 and $0.01 \mathrm{mg} / \mathrm{ml} \mathrm{AgNPs} \mathrm{used} \mathrm{as}$ an adjuvant, compared to the control. However, the cell viability was decreased significantly when $0.1(* * * p<$ $0.001)$ and $1 \mathrm{mg} / \mathrm{ml}(* * * p<0.001)$ concentrations of AgNPs were used, as shown in Fig. 2.

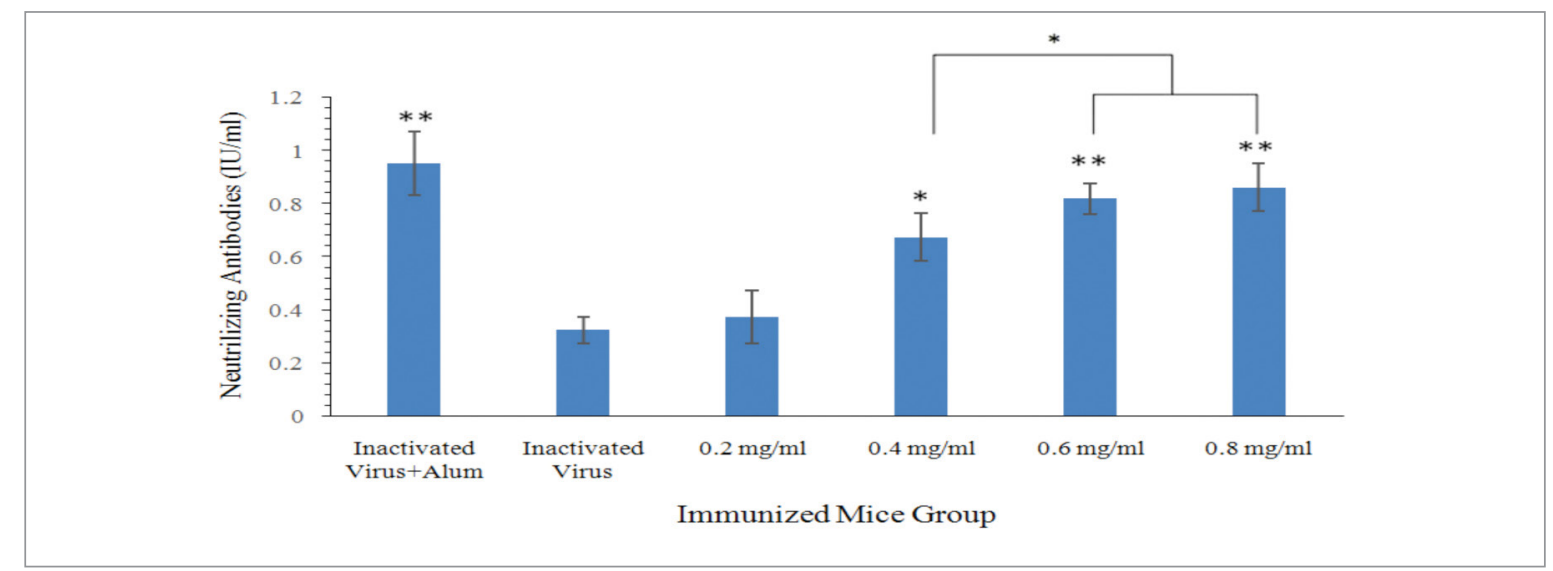

Fig. 1. Determination of neutralizing antibodies in immunized mice injected with different amount of AgNPs, as adjuvant. Alum and inactivated virus were used as positive and negative controls, respectively. All data were presented as Mean \pm SDand significant levels were assumed as follow; $* p<0.05, * * p<0.01$ and $* * * p<0.001$

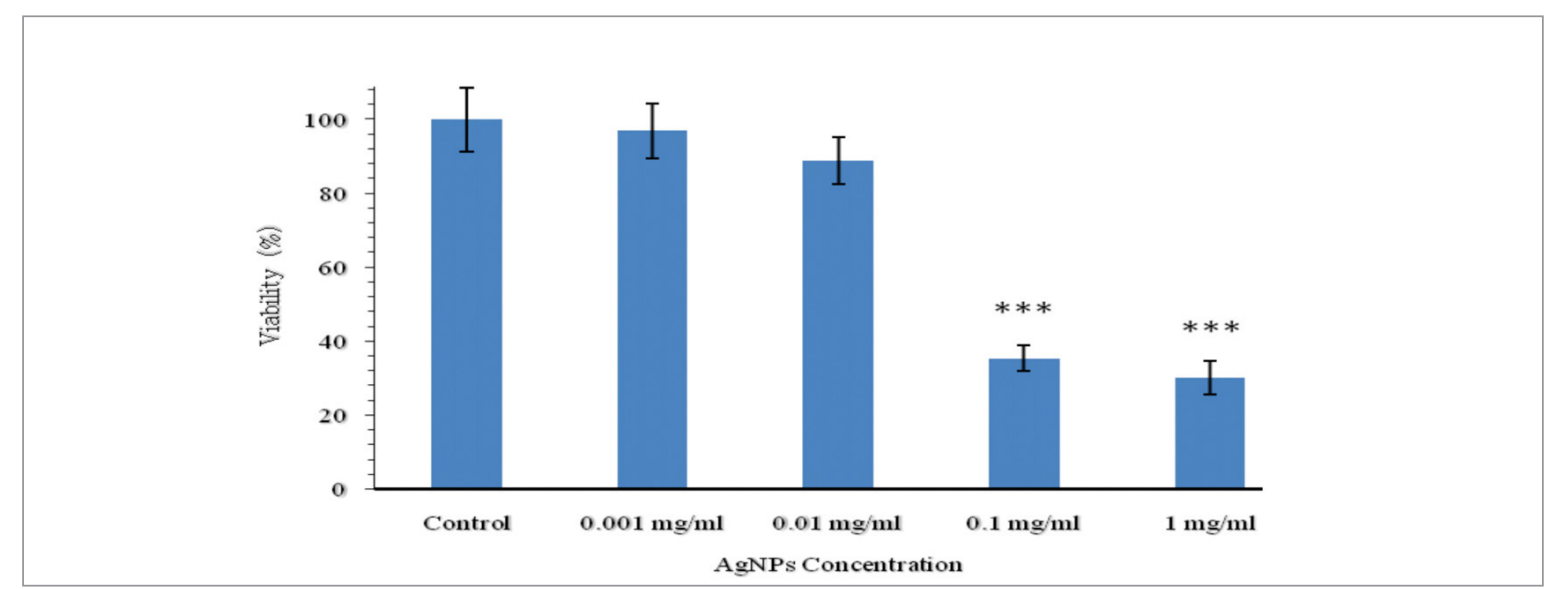

Fig. 2. In vitro toxicity of AgNPs on J774A.1 cell line

DMEM was used as positive control. All data presented as Mean $\pm \mathrm{SD}(\mathrm{Ni}=6)$ and significant levels were assumed as follow; $* p<0.05$, ** $p<0.01$ and $* * * p<0.001$.

\section{DISCUSSION}

In the present investigation, we assessed the adjuvant effect of AgNPs on the rabies vaccine and compared the results to a commercially-available rabies vaccine. The composition of AgNPs has previously been shown by $\mathrm{Xu}$ et al. [10] to be only consisted of silver and oxygen atoms which confirms that the adjuvant effect observed in our study was only due to AgNPs [10]. The mean size of AgNPs in water has been reported to be $141 \mathrm{~nm}$ with a negative charge of $-30.6 \mathrm{mv}$, as determined by Dynamic Light Scattering (DLS) method. Although the toxicity of silver ions has been proven by in vitro and in vivo tests, no toxicity has been reported for AgNPs, due to the fact that the release of silver ions from AgNPs is shown to be negligible [10].
In the current study, the adjuvanticity effect of AgNPs was confirmed, as it has been previously shown by Xu and colleagues that the highest response could be obtained with $\geq 0.4 \mathrm{mg} / \mathrm{ml}(10 \mathrm{mg} / \mathrm{kg})$ AgNPs via i.p. injection. This result was similar to the same report by $\mathrm{Xu}$ 's team regarding their two protein models, namely, Ovalbumin (OVA) and Bovine serum Albumin (BSA) when compared to PBS [10].

It must be noted that the subcutaneous immunization showed better effect because many studies prove that the route of administration plays an important role in stimulation of the immune system [14].

The adjuvanticity of AgNPs was increased with increasing of its concentration and finally reached a plateau which might be the reason for the similarity of the results obtained forthe 15 and $20 \mathrm{mg} / \mathrm{kg}$ concentrations; however 
at these concentrations, the adjuvanticity effect is comparable with Alum. This phenomenon was observed at lower concentrations for both protein modelsin Xu's study ( $2 \mathrm{mg} / \mathrm{kg}$ and $10 \mathrm{mg} / \mathrm{kg}$ for BSA and OVA, respectively) which can be explained by the type of the antigen used. Although they reported that the adjuvanticity effect of AgNPs is not depended on the type of the antigen, it must be noted that they used similar antigens and this may explain the same results obtained for two different proteins whereas the antigen used in the current investigation (i.e. inactivated rabies virus), was a complex antigen [10]. The other reasons may be related to the protocol of the immunization and the type of mice used. We immunized the mice twice with the antigen and the adjuvant whilst they used the adjuvant only at their first administration. Furthermore, it has been reported that $\mathrm{BALB} / \mathrm{c}$ mice which they used in their study have more potent humoral immuneresponses [15]. It is noteworthy that our antigen alone was more immunogenic than BSA or OVA proteins and increasing the immune responses by the adjuvant is undoubtedly more difficult.

The mechanism of AgNPs adjuvanticity is not clearly known but investigations suggest that they act through several mechanisms such as cytokines release, recruitment of leukocytes and up-regulation of major histocompati-bility class II (MHC-II) molecules on peritoneal macrophages [10]. In addition, it has been reported that AgNPs like Alum can stimulate T helper-II depended response leading to the antibody responses. It has also been reported that AgNPs tend to be aggregated in water and this may be an additional mechanism by which they can entrap the antigen and allow sustained delivery of the antigen to the immune system microenvironment [10]. In conclusion, in this study we showed the adjuvanticity effect of AgNPs on rabies neutralizing antibodies.

These results require further assessment using different routes of injections as well as different animal models. Furthermore, the AgNPs adjuvanticity should be tested with a wide range of antigens and its mechanism of action needs to be clarified. Our results were consistent with other studies which clearly showed the effect of AgNPs in increasing the humoral response to the rabies vaccine. However, until further improvements to overcome their adverse effect on cell viability at effective concentrations are not achieved, the use of AgNPs as an adjuvant is not recommended.

\section{ACKNOWLEDGEMENTS}

The authors are grateful to WHO collaborating center for research on Rabies of Pasteur Institute of Iran. We have special thanks to Dr. Aghasadeghi and Dr. Gholami. We are also thankful to Mr. Howaizi for his technical support.

\section{CONFLICT OF INTEREST}

All of the authors have declared that no competing interests exist.

\section{REFERENCES}

1. Harandi AM, Medaglini D, Shattock RJ, Working Group convened by EUROPRISE. Vaccine Adjuvants: A Priority for Vaccine Research. Vaccine, 2010; 28 (12): 2363-6.

2. Perrie Y, Mohammed AR, Kirby DJ, McNeil SE, Bramwell VW. Vaccine Adjuvant Systems: Enhancing the Efficacy of Sub-Unit Protein Antigens. Int J Pharm, 2008; 364 (2): 272-80.

3. Baylor NW, Egan W, Richman P. Aluminum Salts in Vaccines--US Perspective. Vaccine, 2002; 20 (Supp1 3): S18-23.

4. Wang W, Singh M. Selection of Adjuvants for Enhanced Vaccine Potency. WJV, 2011; 1 (2): 33-78.

5. Chang M, Shi Y, Nail SL, HogenEsch H, Adams SB, White JL, Hem SL. Degree of Antigen Adsorption in the Vaccine or Interstitial Fluid and Its Effect on the Antibody Response in Rabbits. Vaccine, 2001; 19 (20-22): 2884-9.

6. Tritto E, Mosca F, De Gregorio E. Mechanism of Action of Licensed Vaccine Adjuvants. Vaccine, 2009; 27 (25-26): 3331-4.

7. Mbawuike I, Zang Y, Couch RB. Humoral and cell-Mediated Immune Responses of Humans to Inactivated Influenza Vaccine with or without QS21 Adjuvant. Vaccine, 2007; 25 (17): 3263-9.

8. Coler RN, Bertholet S, Moutaftsi M, Guderian JA, Windish HP, Baldwin SL, Laughlin EM, Duthie MS, Fox CB, Carter D, Friede M, Vedvick TS, et al. Development and Characterization of Synthetic Glucopyranosyl Lipid Adjuvant System as a Vaccine Adjuvant. PLoS One, 2011; 6 (1): e16333.

9. Akagi T, Baba M, Akashi M. Biodegradable Nanoparticles as VaccineAdjuvants and Delivery Systems: Regulationof Immune Responses by Nanoparticle-BasedVaccine. Adv Polymer Sci, 2012; 247: 31-64.

10. Xu Y, Tang H, Liu JH, Wang H, Liu Y. Evaluation of the adjuvant effect of silver nanoparticles both in vitro and in vivo. Toxicol Lett, 2013; 219 (1): 42-8.

11. Hicks DJ, Fooks AR, Johnson N. Developments in rabies vaccines. Clin Exp Immunol, 2012; 169 (3): 199-204.

12. Kostense S, Moore S, Companjen A, Bakker AB, Marissen WE, von Eyben R, Weverling GJ, Hanlon C, Goudsmit J. Validation of the rapid fluorescent focus inhibition test for rabies virus-neutralizing antibodies in clinical samples. Antimicrob Agents Chemother, 2012; $56(7): 3524-30$.

13. Oscherwitz J, Hankenson FC, Yu F, Cease KB. Low-Dose Intraperitoneal Freund's Adjuvant: Toxicity and Immunogenicity in Mice Using an Immunogen Targeting Amyloid-Beta Peptide. Vaccine, 2006; 24 (15): 3018-25.

14. Stertman L, Strindelius L, Sjoholm I. Starch Microparticles as an Adjuvant in Immunization: Effect of Route of Administration on the Immune Response in Mice. Vaccine, 2004; 22 (21-22): 2863-72. 15. Pellegrini A, Guiñazú N, Aoki MP, Calero IC, Carrera-Silva EA, Girones N, Fresno M, GeaS. Spleen B cells from BALB/c are more prone to activation than spleen $\mathrm{B}$ cells from $\mathrm{C} 57 \mathrm{BL} / 6$ mice during a secondary immune response to cruzipain. Int Immunol, 2007; 19 (12): 1395-402. 